\title{
ADDENDUM TO \\ “A NECESSARY AND SUFFICIENT CONDITION FOR \\ A LOWER BOUND FOR FOURTH-ORDER PSEUDODIFFERENTIAL OPERATORS"
}

By

Cesare Parenti and Alberto ParmegGiani

Journal d'Analyse Mathématique 69 (1996), 55-65

\begin{abstract}
After the paper was in the press, we found, while searching through the literature, the paper by A. Mohamed, Etude spectrale d'opérateurs hypoelliptiques à caractéristiques multiples, II, Comm. Partial Differential Equations 8 (1983), 247316 , in which he proves, among other general results, the lower bound we were concerned with, without making use of condition (HS). Since we were not aware of the aforementioned paper, we would like to acknowledge its existence and give Mohamed's work the proper credit. We apologize for not having been complete in our references.
\end{abstract}

